\title{
Organizational Learning Capability and Academician's Work Innovativeness
}

\author{
Tan Cheng Ling ${ }^{1}$ and Lim Chuang Way ${ }^{2}$ \\ ${ }^{1,2}$ Graduate School of Business, Universiti Sains Malaysia, Penang, Malaysia \\ tanchengling@usm.my
}

\begin{abstract}
The present research examined the relationship between organizational learning capability (management commitment, system perspective, openness and experimentation, and knowledge transfer and integration) and the academician's work innovativeness. The data were derived from the survey returned by 105 academicians from private higher education institutions (PHEIs) in Malaysia. The Results from the regression analysis revealed that management commitment, and openness and experimentation were positively related to academician's work innovativeness. The theoretical and practical implications of the study as well as suggestion for future studies were also discussed.
\end{abstract}

Keywords: academicians, work innovativeness, organizational learning capability, private higher education institutions.

\section{Introduction}

In this rapid change of economics, many higher education institutions (HEIs) are striving to remain competitive in order to expand and gain advantage over other competitors. The rising demand for higher education has expanded the growth of PHEIs in the country since 1980s. This is evident with a significant increment of 10.6 percent of students enrolled in PHEIs from 2009 to 2010 (MOHE, 2011). In response to the com- petition in the local market, many PHEIs have gone worldwide to bring foreign students into the country that will help in generating the Gross National Income (GNI) to the country. However, the increment of 7 percent of foreign students' enrolment from 58,294 in 2009 to 62,705 in 2010 (MOHE, 2011) was not sustained. Based on Ministry of Higher Education, total foreign students enrolment in Malaysia went down to 45,246 in 2011 from 62,705 in 2010 , which has recorded a sharp decrease of $27 \%$. In this regard, the academician's lecturing qualities and work innovative behaviour became the subject of numerous discussions among practitioners and researchers.

Academicians should identify, support, and preserve learning as a valuable tool for obtaining long-term benefits (Garcia-Morales, Lopez-Martin, \& Llamas-Sanchez 2006). Hence, an academician' roles are not only to grant information about a subject matter, but also to disseminate knowledge to the students effectively through teaching and learning. The academician's capabilities to disseminate and share knowledge are essential determinants in shaping the academician's work innovativeness. The academician's work innovativeness takes account of increasing professional experience through innovation, flexibility of professional structure values, selfconfidence, and enthusiasm in teaching and learning, which shall be continuously augmented. This entails that organizational learning capability which regarded 
as an organization's capability to process knowledge and to transform its behavior to reflect the new cognitive situation (Jerez-Gomez, Cespedes-Lorente, \& ValleCabrera 2005; Sinkula, 1994) shall be treated with particular thought.

Organizational learning capability is the fundamental for individual learning (Liao \& Wu, 2010), and is required to inspire academician's work innovativeness. Institution with organizational learning capability is likely to encourage its academicians to share knowledge which in turn create organizational memory in the form of shared belief; make assumptions and norms (Sinkula, 1994). Given the point of academician's work innovativeness in enhancing the institution's growth and performance, the potential role of organizational learning capability in motivating the academician's work innovativeness; investigating the influence of this variable on academician's work innovativeness among PHEIs is merited.

\section{Literature Review}

\subsection{Work Innovativeness}

PHEIs require their academicians to engage in innovative work behavior to create and deliver their professional services in order to stay competitiveness. An institutions cannot be innovative itself without its people. Many practitioners and researchers support the fact that innovative work behavior helps to make organizational success (Chang \& Liu, 2008; Yuan, 2008). Work innovativeness is regarded as a multi-dimensional behavior which enables individual to contribute to the process of innovation (Jong \& Hartog, 2008). In regard to this study, academician's work innovativeness is referred to the development, renewal and expansion of the knowledge and skill in teaching and learning job (Chang, Yeh, Chen, \& Hsiao, 2011). An academician's work innovativeness is depended on their knowl- edge that can be obtained through experience, and then presented with manifestation and innovation through wide-ranging activities (Chang, et al., 2011).

\subsection{Organization Learning Capability}

Organizational learning is regarded as one of the strategic means of achieving sustainable organizational accomplishment (Liao \& Wu, 2009). Institutions with organizational learning capability can create growth through global diversification, new applications of existing technologies, and/or creation of new lines of business thus achieving competitive advantage (Lei, Hitt \& Bettis, 1996). Drawing on the works of numerous researchers, organizational learning capability has been regarded as the organization's ability to continuous process, integrate and support organizational learning environment fits the most to this study. Therefore, through extensive literature reviews (Jerez-Gomez, et al., 2005; Liao \& Wu, 2010; Ussahawanitchakit, 2008; Akgun et al., 2007), the four widely cited dimension of organizational learning capability that comprises of managerial commitment; system perspective; openness and experimentation; and knowledge transfer and integration; were chosen as the important predictors for academician's work innovativeness.

\subsection{Work Innovativeness and Organi- zation Learning Capability}

Despite the importance of constant learning, which can improve an institution's competitiveness, there is still debate about how managers can efficiently develop a learning capability in their institutions (Jerez-Gomez, et al., 2005). Numerous studies (Akgun, Keskin, Byrne \& Aren, 2007; Alegre \& Chiva, 2008; Chang, et al., 2011; Garcia-Morales, et al., 2007; Liao \& Wu, 2010) have recognized the influence of organizational learning capability on innovation. However, to the 
researchers' knowledge, not much research has been carried out on the academician's work innovativeness. Organizational learning capability enables the academicians to continuously looking for new and innovative way in their teaching and learning; as well as research works, which will in turn increase their work innovativeness. In consequence, organizational learning capability is hypothesized to confer a positive influence on the academician's work innovativeness. Our main hypothesis is constructed as follows:

$\mathrm{H}_{1}$ : Organizational learning capability (managerial commitment, system perspective, openness and experimentation, knowledge transfer and integration) has a positive influence on academician's work innovativeness.

Management commitment is referred as the ability of institutions to develop and facilitate leadership management and managerial support for the innovation process and employee motivation in creating and building knowledge in an institution (Ussahawanitchakit, 2008). This study projected that the higher level of management commitment, the higher level of academician's work innovativeness. Thus, the first sub-hypothesis is postulated as below:

$\mathrm{H}_{1.1}$ : Management commitment has a positive influence on academician's work innovativeness.

System perspective is termed as the ability of institutions to bring organizational members together around a common identity and a shared vision, interconnect the activities of employees which include the promotions of joint actions, and develop relationships based on the exchange of information and shared mental models (Ussahawanitchakit, 2008). The system perspective institutions will bring their academicians together to exchange and share information which will later increase their work innovativeness.
Hence, the second sub-hypothesis is presented as below:

$\mathrm{H}_{1.2}$ : System perspective has a positive influence on academician's work innovativeness.

Openness and experimentation is regarded as the ability of firms to build a climate of openness and experimentation in accepting new ideas and points of view in both internal and external aspects (Ussahawanitchakit, 2008). This climate allowing individual knowledge to constantly improve, renew, and widen which in turn increase the academician's work innovativeness. Therefore, the third subhypothesis is conjectured as below:

$\mathrm{H}_{1.3}$ : Openness and experimentation has a positive influence on academician's work innovativeness.

Knowledge transfer and integration is defined as the ability of institutions to internally spread knowledge through the verbal and nonverbal communications, which include formal and informal conversations, debate, dialogue and interaction among individuals, and effectively exploiting knowledge through the information systems (Ussahawanitchakit, 2008). This will aid in the availability, accuracy, and reproducibility of the information which will then utilize by the academicians in aiding their work innovativeness. For this reason, the fourth subhypothesis is formulated as below:

$\mathrm{H}_{1.4}$ : Knowledge transfer and integration has a positive influence on academician's work innovativeness.

\section{Methodology}

Questionnaires were distributed to a total of 680 academicians from a total of 68 PHEIs located in northern, central and southern of Peninsular Malaysia. The list of PHEIs was obtained from the Ministry of Higher Education, 2011 (JPT, 2011). Ten questionnaires were sent to the academicians in each PHEI via academics 
unit in the institution. Five questionnaires were distributed to the academicians from faculty of Business and Management, and another five questionnaires to the academicians from Engineering/Information Technology faculties. The academicians from these two faculties are given priority to participate due to most of the PHEIs have these faculties in their institutions. The respondents should be academicians holding a position as professor, associate professor, senior lecturer, and lecturer in the institution. The participating firms were given a month to complete the questionnaires.

\section{Results}

\subsection{Profile of Respondents}

After the stipulated period, 116 questionnaires were returned, and only 105 questionnaires were found to be usable. This represented a response rate of 15.44 percent. Of 105 respondents, 64.8 percent are male while only 35.2 percent are female. In connection with respondent's job position, 82.8 percent hold the position as lecturer while another 12.4 percent are senior lecturer. The remaining respondents are professor $(2.9 \%)$ and associate professor (1.9\%).

\subsection{Descriptive Statistic}

The descriptive statistic revealed that the mean age of respondents is 41.19 (SD = 10.75), ranging from a minimum of 26 years to a maximum of 67 years. The mean for organizational tenure is 5.50 $(\mathrm{SD}=3.65)$, ranging between 1 year to 18 years. Reliability analysis was used to measure the internal consistency to ensure the individual items measuring the same constructs are highly intercorrelated (Hair, Black, Babin, Anderson, \& Tatham, 2006). Cronbach's alpha for academician's work innovativeness was 0.91. Meanwhile, the cronbach's alpha value for organizational learning capability dimensions were between from 0.79 to 0.86. All the cronbach's alpha for variables met the minimum accepted reliability of 0.60 as proposed by Sekaran (2003).

The means of four dimensions of organizational learning capability (managerial commitment; system perspective; openness and experimentation; and knowledge transfer and integration) ranged from 3.84 to 3.93 are perceived as being relatively high by respondents: management commitment $(\mathrm{M}=3.93, \mathrm{SD}$ $=0.67)$, knowledge transfer and integration $(\mathrm{M}=3.93, \mathrm{SD}=0.61)$, openness and experimentation $(\mathrm{M}=3.85, \mathrm{SD}=0.65)$, system perspective $(\mathrm{M}=3.84, \mathrm{SD}=0.59)$. Respondents perceived academician's work innovativeness to be relatively high as well with mean score of 3.85 (SD = $0.53)$.

\subsection{Multiple Regression Analysis}

Regression was conducted to test the hypotheses for this study. Table 1 shows the regression analysis of organizational learning capability on academician's work innovativeness. From the model 1 in Table 1, three control variables namely age, gender and organizational tenure produced a coefficient determination ( $R$ square value) of 0.04 which means that only $4 \%$ of the variance in academician's work innovativeness is explained by these three variables. The results indicate no significant contribution towards the variance in academician's work innovativeness. From model 2, out of four organizational learning capability, management commitment $\quad(\beta=0.22, \quad \mathrm{p}<0.05) ;$ and openness and experimentation $(\beta=0.40$, $\mathrm{p}<0.01)$ was found to be significant and positively related to academician's work innovativeness. Therefore, two out of four sub-hypotheses $\left(\mathrm{H}_{1.1}\right.$ and $\left.\mathrm{H}_{1.3}\right)$ were supported, while the remaining two $\left(\mathrm{H}_{1.2}\right.$ and $\mathrm{H}_{1.4}$ ) were not supported. This con- 
cludes that hypothesis $\mathrm{H}_{1}$ is partially supported.

Table 1: Regression Analysis of Organizational Learning Capability on Innovation of Professional Development.

\begin{tabular}{|l|c|c|}
\hline Predictors & $\begin{array}{c}\text { Model 1 } \\
\text { Std. } \beta\end{array}$ & $\begin{array}{c}\text { Model 2 } \\
\text { Std. } \beta\end{array}$ \\
\hline Control Variables & 0.10 & -0.04 \\
Age & 0.11 & 0.05 \\
Gender & -0.16 & -0.09 \\
Organizational Tenure & & \\
\hline Organizational & & \\
Learning Capability & & $0.22^{*}$ \\
Management Com- & & 0.15 \\
mitment & & $0.40^{* *}$ \\
System Perspective & & 0.07 \\
Openness and Exper- & & \\
imentation & & 0.50 \\
Knowledge Transfer & & 0.47 \\
and Integration & & 0.47 \\
\hline R Square & 0.04 & $13.95^{* *}$ \\
Adjusted R Square & 0.01 & $22.73^{* *}$ \\
R Square Change & 0.04 & 1.20 \\
F-Value & 1.20 & \\
$\Delta$ F-Value & & \\
\hline
\end{tabular}

Note: $* \mathrm{p}<0.05, * * \mathrm{p}<0.01$

\section{Discussion and Conclusion}

Two organizational learning capability dimensions were significant and positively related to academician's work innovativeness. Openness and experimentation ( $\beta=0.40, p<0.01)$, was found to be the strongest predictor. It was then followed by Management commitment $(\beta=0.22$, $p$ $<0.05)$. Academicians perceive management commitment to be positively and significantly related to their innovation of professional development. There is no doubt in the results as management is responsible to create learning and innovative culture in their institutions in order to promote academician's work innovativeness. This is in line with findings from Chang et al, (2011) concluded that management should construct a comfortable learning culture with collaborative teams for improvement of innovation learning and knowledge sharing. Besides creating culture, management that provides incentives to academicians in rewarding their work innovativeness will help academicians to reinforce best practices in contributing to institution's knowledge (Adhikari, 2010). The positive relationship between openness and experimentation and academician's work innovativeness is congruent with Jerez-Gomez, et al., (2005). The results is rather expected as openness and experimentation will promote academician's work innovativeness to constantly generating new ideas and points of view thus allowing academician's knowledge to be constantly renewed, improved and widened (JerezGomez, et al., 2005).

System perspective and knowledge transfer and integration were found to be insignificant to academician's work innovativeness. Academicians did not perceive system perspective to be related to their work innovativeness probably due to the lack of collaboration between departments. As a result, each department has its own function and academicians performing according to the needs of their department rather than meeting institution's overall objectives. Knowledge transfer and integration showed insignificant effect on academician's work innovativeness may be explained by the lacking of human values, trust and team spirits among academicians. Without trust and team spirit, knowledge transfer and integration among individuals will never take place (Gupta, Lyer, \& Aronson, 2000). The result of this study offers several suggestions to PHEIs in Malaysia. In particular, the management could use the results to encourage academician's work innovativeness by strengthening the organizational learning capability in the institution.

Note: This paper is funded by Research Creativity and Management Office (RCMO), Universiti Sains Malaysia. 


\section{References}

[1] A. E. Akgun, H. Keskin, J. C. Byrne, \& S. Aren (2007). Emotional and learning capability and their impact on product innovativeness and firm performance. Technovation, 27, 501513.

[2] B. Gupta, L. S. Lyer \& J. E. Aronson, (2000). Knowledge Management: Practices and Challenges.

[3] D. Lei, M. A. Hitt, \& R. Bettis (1996). Dynamic Core Competences through meta-learning and strategic context. Journal of management, 22, (4), pp. 549-569.

[4] D. R. Adhikari, (2010). Knowledge management in academic institutions. International Journal of Educational Management, 24 (2), pp. 94-104.

[5] F. Yuan, (2008). Individual innovation in the workplace: The role of performance and image outcome expectations. Ph.D. Dissertation, Texas A\&M University, Texas., United States.

[6] J. Alegre \& R. Chiva (2008). Assessing the impact of organizational learning capability on product innovation performance: An empirical study. Technovation, 28, 315-326.

[7] J.-C. Chang, Y.-M. Yeh, S.-C. Chen, \& H.-C. Hsiao, (2011). Taiwanese technical education teacher's professional development: An examination of some critical factors. Teaching and teacher education, 27 (1), pp. 161173.

[8] J. F. Hair, B. Black, B. Babin, R. E. Anderson \& R. L. Tatham, (2006). Multivariate Data Analysis. Upper Saddle River, NJ: Prentice Hall.

[9] J. M. Sinkula (1994). Market Information Processing and Organizational Learning. Journal of marketing, 58, pp. 35-45.
[10] JPT. (2011). List of IPTS. Retrieved June 21, 2011, from http://jpt.mohe.gov.my/menudirektori .php

[11] L.-C. Chang, \& C.-H. Liu (2008). Employee empowerment, innovative behavior and job productivity of public health nurses: A cross-sectional questionnaire survey. International Journal of Nursing Studies, 45 (10), pp. 1442-1448.

[12] MOHE (2011). The National Education System. Retrieved February 20, 2012 from

http://www.portal.mohe.gov.my/porta 1/page/portal/ExtPortal/Agencies/Stud y_in_Malaysia/National_Education_S ystem

[13] P. Jerez-Gomez, J. CespedesLorente, \& R. Valle-Cabrera, (2005). Organizational learning capability: A proposal of measurement. Journal of Business Research, 58, pp. 715-725.

[14] P. Ussahawanitchakit (2008). Organizational learning capability, organizational commitment, and organizational effectiveness: an empirical study of Thai accounting firms. International Journal of Business Strategy, 8 (3), pp. 1-12.

[15] S. H. Liao, \& C. C. Wu, (2010). System perspective of knowledge management, organizational learning, and organization innovation. Expert Systems with Applications, 37, pp. 1096-1103.

[16] U. Sekaran (2003). Research Methods for Business: A skill building approach (4th edition). New York: John Wiley \& Sons.

[17] V. J. Garcia-Morales, F. J. LopezMartin, \& R. Llamas-Sanchez, (2006). Strategic factors and barriers for promoting educational organizational learning. Teaching and teacher education, 22 (4), pp. 478-502. 